\title{
Methodology for Calculating the Potential Maritime Wind Park Area by Taking into Account the Needs of Shipping Sector
}

\author{
Astrida Rijkure \\ Scientific Institute of Economics and Management, University of Latvia, Riga, Latvia
}

\begin{abstract}
Renewable energy sources (wind energy, solar energy, hydroelectricity, ocean energy, geothermal energy, biomass and biofuels) are alternatives to fossil fuel that help to reduce greenhouse gas emissions, diversify energy supplies and reduce dependency on markets of unsustainable and volatile fossil fuels, particularly oil and gas. Wind energy is one of the renewable energy sources and is considered to be self-renewable as it is the result of the Sun's activity. Using wind energy is a rapidly developing industry today, and more and more wind turbines are installed worldwide every year, land-based wind turbines being more widespread than offshore ones. In Latvia, spread of land-based wind parks is hampered by unsettled land ownership rights, while the deployment of wind parks in the sea is a new field for all Baltic States. The neighbouring countries Estonia and Lithuania have developed their own projects for offshore wind parks, therefore the topicality of the development of wind farms in the territorial waters of Latvia has also increased. Experts have proposed best options and their locations. When assessing possibilities for development of wind parks and their capacity, the following economic factors were evaluated: construction and connection costs, potential operational costs and energy prices. The aim of this study is to develop the methodology for calculating the area of a potential wind park by considering the safety distance to shipping routes and height of the wind turbines, as well as for calculating the potential capacity of a wind park.
\end{abstract}

\section{Introduction}

Wind energy is electric power that is generated by means of wind turbines. [1] Wind energy is produced, as wind encounters an obstacle on its way and transfers a portion of its kinetic power to such obstacle. This principle is used in wind turbines, or wind generators, where wind moves turbine blades, generating mechanical power, which is then transformed into electricity by means of generators. [2] More and more attention must be paid to methods of generating alternative power. The use of alternative energy allows reducing the costs of heating, it is friendlier for the environment (non-renewable resources that cause environmental pollution from their use, like coal, oil or natural gas, are not used) and increases the autonomy from suppliers of traditional energy resources.

Wind energy is considered to be an energy that is capable of renewing itself, since it is the consequence of the Sun's activity. The use of wind power is an industry that is developing very rapidly. More and more wind turbines are installed worldwide every year. A total of approximately $460 \mathrm{GW}$ of wind power is generated worldwide every day, which amounts to about $4 \%$ of the total power generation and consumption worldwide. Wind turbines are frequently installed on land or above water bodies like oceans or seas and, usually, the turbines installed on land are capable of generating power for the cheapest price, as the investment pays off in less than 10 years since installation thereof. While turbines installed in the sea are more expensive and the care for them, as well as their maintenance is more expensive, their power generation properties are also better, because wind blows on the surface of water bodies almost all year round.

Wind turbines are usually considered to be the least predictable method of generating power, since the output of power by one turbine can change even within the limits of $10 \%$ over a period of an hour, which can cause different problems. Usually wind turbine parks are developed in a wide area and consist of multiple individual turbines, which makes the total amount of generated wind power more predictable since changes in weather conditions can be predicted a day in advance, thus the total electricity consumption in the region is increased or reduced and the electricity is transferred via the grid to other areas. Wind power can be successfully linked with hydroelectric plants, which can control the generated electric power.

Despite the drawbacks and advantages of wind installations, their use benefits the surrounding environment. Wind energy is a limitless resource that does not produce hazardous waste. Installation of such stationary structures in the sea requires respect for the shipping industry, which is already operating in the seas, meaning that safe distances to wind turbines must be determined to ensure that in the event of wind energy structures falling into water, they would not endanger nearby ships. 


\section{Safe distance of shipping routes from stationary sea structures}

Marine Spatial Planning (MSP) will become an increasingly important issue for the shipping sector over the next few years. Maritime professionals need to engage with other users of waterways space, from both a sea and shore perspective, and to take part in international, regional, national and local MSP debates, to ensure that the needs of the shipping sector are taken into full consideration and that the sector understands the needs of other marine users and resources.

MSP has the potential to address the impacts of all activities in a specific place, so that marine ecosystems can be productive, resilient to change, and accommodate appropriate, responsible economic activities. Several countries are developing MSP approaches to address fragmented management schemes that do not adequately tackle the complex interactions of the myriad activities that occur simultaneously on and in waterways.

Growth in the world economy is expected to result in an increase in ship traffic in certain areas, all in decreasingly available sea space. In addition, there will be challenges for such waters from industries such as oil an gas, offshore renewable energy, commercial fishing, recreational craft, aggregate dredging, mining, fish farms and government imposed restricted areas. [6]

Several provisions, which were adopted at a time when technology was not advanced to the contemporary level, must be observed in order to determine the safe distance to stationary constructions, which among others includes wind turbines.

The following regulations and guidelines have been developed on the international level:

- The General Provisions on Ships' Routeing (GPSR) adopted by International Maritime Organisation in 1974 [7]

- The United Nations Convention on the Law of the Sea (UNCLOS) adopted by the United Nations in 1982 [9]

- International Regulations for Preventing Collisions at Sea (COLREG) adopted 1972 [2]

$\checkmark$ GPSR 6.4 Course alteration along a route should be as few as possible and should be avoided in the approaches to convergence areas and route junctions or where crossing traffic may be expected to be heavy.

The captain must keep a safe distance from stationary structures. Meanwhile, stationary structures may not be installed in the sea in a manner that forces ships to change their course to keep a safe distance.

$\checkmark$ GPSR 6.8 Traffic separation schemes shall be designed so as to enable ships using them to fully comply at all times with the International Regulations for Preventing Collisions at Sea (COLREG), adopted in 1972.

Safe distance to the constructions must be determined in the manner that enables the ship to operate in compliance with COLREG at all times - including cases, where the shipping occurs on the delimiting lines.

$\checkmark$ GPSR 6.10 Traffic lanes should be designed to make optimum use of available depths of water and the safe navigable areas, taking into account the maximum depth of water attainable along the entire length of the route. The width of lanes should take account of the traffic density, the general usage of the area and the sea-room available.

$\checkmark$ UNCLOS Section 6, article 60. All ships must respect these safety zones and shall comply with generally accepted international standards regarding navigation in the vicinity of artificial islands, installations, structures and safety zones.

The safety zone of $500 \mathrm{~m}$ described in Section 6 is intended for the protection of the structure and not safe manoeuvring in accordance with COLREGs.

$\checkmark$ COLREGS 8 Action taken to avoid collision with another vessel shall be such as to result in passing at a safe distance. The effectiveness of the action shall be carefully checked until the other vessel is finally past and clear.

There are no regulations pertaining to anchoring sites. However, sufficient manoeuvring area must be ensured for safe anchoring: when the anchor is sliding, while getting closer to anchoring sites. The safety research of coast platforms demonstrates that the area that is required for a ship to start the engines and manoeuvre, when the anchor is dragged, is 1.7 sea miles from the safety zone around stationary structures. It has been detected that such distance is sufficient, as ships that us this particular area of water for anchoring are approaching [10].

Standard turning circles for vessels are six times the ship's length. This is a particularly good assumption for vessels on ocean or deep sea passage, which will not have the same manoeuvrability as when engines and systems are prepared for port approach. Requirements for stopping in an emergency must be considered, for example in case of a steering gear failure. The crash stop distance for a large tanker may be up to $3 \mathrm{~km}$.

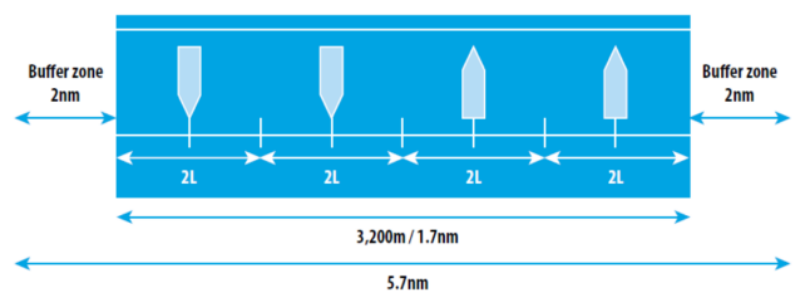

Fig. 1. An example of recommended minimum shipping lane width between two adjacent windfarms considering vessels of $400 \mathrm{~m}$ in len [6].

It is important to keep a safe distance between shipping corridors and sea wind parks in order to coordinate the interests of shipping and energy sectors. Currently no international document that regulates mandatory and safe distances is in effect. As sea wind parks are developing worldwide, both developers of wind parks, as well as organisations involved in the shipping sector, have to develop a document on an international level, which would regulate safe distances between stationary structures in the sea and a shipping route. The document could be used as a guideline when selecting the potential wind park sites and regulations for ships sailing in the seas close to wind parks. 


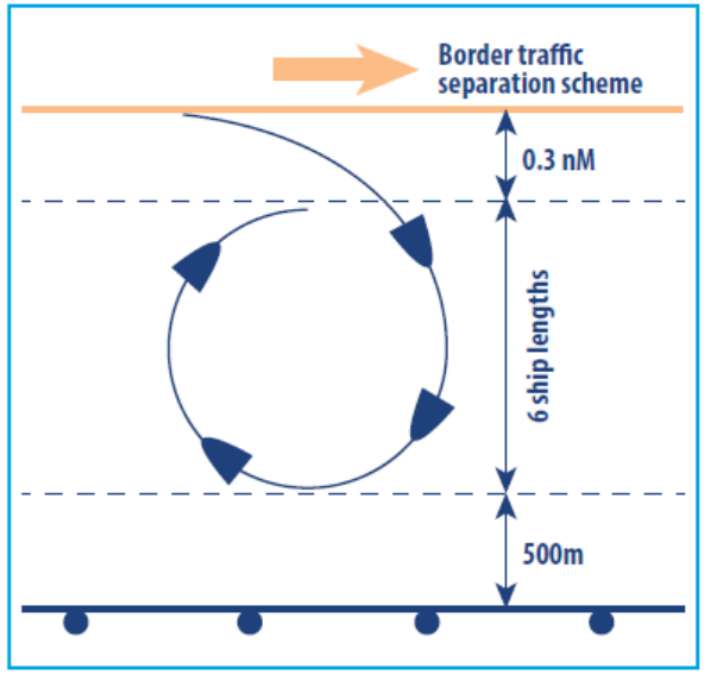

Fig. 2. The width of the shipping route to turn the ship in the opposite direction (SEE COLREGS 8, P13 [2;6]).

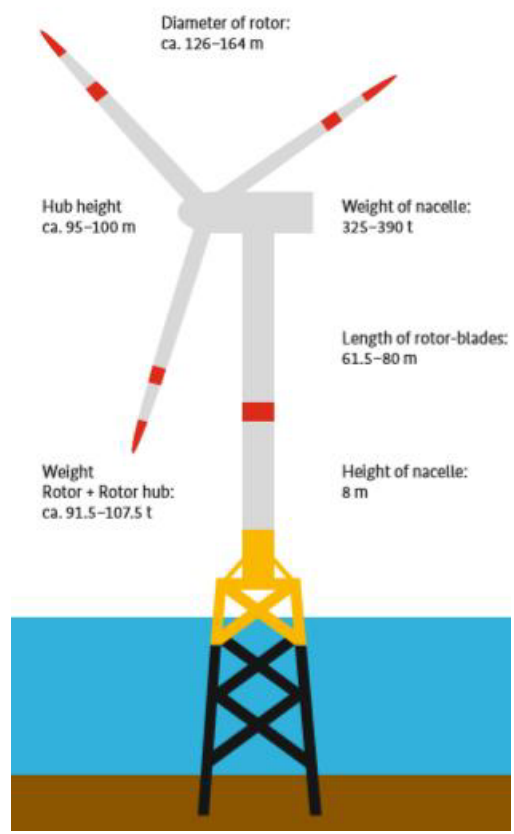

Fig. 3. Standard wind turbine size in Baltic sea region [8].

In the future, greater demands for ships to navigate closer to navigational hazards while ensuring high levels of safety may require new services and technology, in which case serious consideration will need to be given to issues of authority and liability. Evolving navigation technology may provide greater reliability and accuracy of automated electronic position fixing systems. Cheaper communication with greater bandwidth may lead to better provision of critical information and decision support tools for the navigator. Increased traffic density in increasingly constricted water space may require isolation zones for different ocean users such as commercial shipping, fishing and leisure craft [5].

The main components of a wind turbine are the foundation of the tower, the nacelle and the rotor. Although the construction of the turbines is the same on land and at sea, some components differ depending on the varying conditions.

The tower is the longest part of a wind turbine. It supports the nacelle and the rotor. The nacelle houses the components required for the operation of a plant, such as the main bearings, gearboxes, generators, the drive shaft and the control and security systems. The hub and three rotor blades are part of the rotor. The former connects the rotor blades to the rest of the machine and transfers the energy that is generated. The weight of a wind power plant often exceeds 1,000 tonnes.

These days, many operators are planning plants with a capacity of five to seven megawatts. Due to the higher investment costs on the high seas, these systems are installed with a stronger capacity, to generate more energy from the wind. Several manufacturers are working to increase power capacity to further raise energy production between ten and fifteen megawatts per plant. As the capacity increases, the diameter of the rotor becomes larger as well. Rotors used in German projects currently span between 107 and 126 metres, while the latest plants boast rotor diameters of 150 metres.

In order to determine the area required for the falling of one wind turbine during an accident, it is important to consider the height of the wind turbine and calculate the complete perimeter, or the area of the circle that must be allocated for the possible falling of a single wind turbine into the water.

In order to perform such calculations, the area of a circle or one wind turbine safety area, which is calculated in accordance with the formula:

$$
S=\pi R^{2}
$$

where:

$\mathrm{R}$ is the radius of the circle, in this case $\mathrm{R}=$ the height of the wind turbine and $\pi \approx 3.14$

Assuming that a safe distance of shipping from stationary structures is the height of the wind turbine $\mathrm{R}+$ $500 \mathrm{~m}$. The direction of the falling of the wind turbine during an accident cannot be predicted, therefore a circular line around the turbine with the radius equal to the height of the turbine must be drawn.

If the safe perimeter for sailing around one wind turbine, as well as the area of the potential wind park in $\mathrm{m}^{2}$ is determined, the calculations can be done regarding the quantity of wind turbines that can be installed at safe distances.

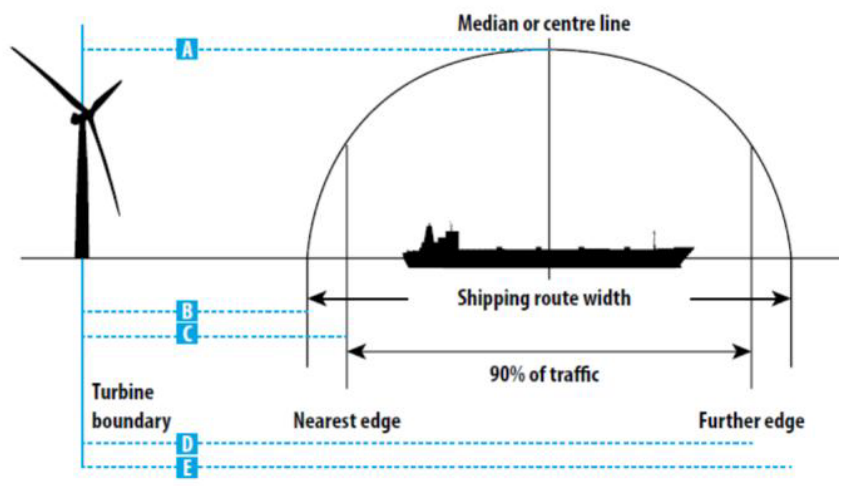

Fig. 4. Wind park safe distance from the shipping route [6]. 
A - turbine boundary to the shipping route median or centre line;

$\mathrm{B}$ - turbine boundary to nearest shipping route edge;

C - turbine boundary to nearest shipping $90 \%$ traffic level;

D - turbine boundary to further shipping $90 \%$ traffic level;

E - turbine boundary to further shipping route edge.

The number of wind turbines in the wind park can be calculated in accordance with the following formula:

$$
W_{T}=\frac{S_{w}}{\pi(R+k \geq 500 m)^{2}}
$$

where:

$W_{T}$ - the number of wind turbines in the wind park,

$\mathrm{R}$ - the height of a wind turbine,

$S_{w}$ - the area of the potential wind park $\mathrm{m}^{2}$,

$\mathrm{k}$ - the safe distance of shipping from stationary structures in the sea,

$\pi \approx 3.14$

2. the formula has been derived by the author.

The performance of such calculations, while performing research and determining the area that may be allocated to the potential wind park in the sea, enable the planners of a sea area to calculate how many wind turbines can be placed in the planned wind park at safe distance from shipping routes.

As the world presses for greater use of the world's waterways, within a framework of sustainability and economic growth, it is inevitable that established commercial shipping operations will be challenged. Society will need to manage the demands of the multitude of stakeholders all wishing/demanding to use inland waters, coastal and ocean pace. Within the embryonic process of MSP, the many stakeholders involved won't always understand the needs and operational requirements of other stakeholders and the impact changes will have upon them and the society that they support.

This case study demonstrates that our understanding of how maritime activities affect marine ecosystem functioning is not yet sufficient for MSP to resolve conflicts. It also highlights potential interactions between the MSFD and other EU policies such as the EU Renewable Energy Sources Directive, the Common Fisheries Policy, Blue Growth, and the proposed MSP directive. In contrast to the first case study, OWF is in direct competition with other maritime activities for space and, while many environmental effects are on-site, there are a number of potential effects at much larger spatial, including transboundary, and temporal scales.

\section{Conclusions}

1. The captain of the ship must keep a safe distance from stationary structures in the sea. Meanwhile, stationary structures may not be installed in the sea in a manner that forces ships to change their course to keep such a safe distance. It is important to keep a safe distance between shipping corridors and sea wind parks in order to coordinate the interests of the shipping and energy sectors. The regulatory enactments that are currently effective have been drawn up for the needs of 1972 - 1982, when the shipping intensity and the proportion of stationary structures considerably differed from current figures.

2. Currently there is no international document that regulates the mandatory and safe distance of shipping routes from stationary structures in the sea. As sea wind parks are developing worldwide, both developers of wind parks, as well as organisations involved in the shipping sector, have to develop a document on an international level which would regulate the safe distance between stationary structures in the sea and shipping routes.

3. In order to determine the area required for the falling of one wind turbine during an accident, it is important to consider the height of the wind turbine and calculate the complete perimeter, or the area of the circle that must be allocated for the possible falling of a single wind turbine into the water. The author proposes to use the formula for the determining the area of a circle for such calculations. Assuming that a safe distance of shipping from stationary structures is the height of the wind turbine $\mathrm{R}+500 \mathrm{~m}$. The direction of the falling of the wind turbine during an accident cannot be predicted, therefore a circular line around the turbine with the radius equal to the height of the turbine must be drawn.

4. The author has deducted her own formula for the planners of sea areas that enables them to calculate how many wind turbines can be placed in the planned wind park at a safe distance from shipping routes, while performing research and determining the area that may be allocated to potential wind parks in the sea.

\section{Acknowledgment}

ERDF project No. 1.1.1.2/VIAA/1/16/061 "Long-term impact of blue economy on the increase of the competitiveness of ports in the Baltic Sea region"

\section{References}

1. Baltic Sea Region Energy Co-operation analysis "Conditions for deployment of wind power in the Baltic Sea Region"/ [online] [26.02.2018]. Available at: $\quad$ http://basrec.net/wpcontent/uploads/2013/09/BASREC-wind2_strategic-outline_120424.pdf

2. COLREGS - International Regulations for Preventing Collisions at Sea, [online] [10.03.2018]. Available at: http://www.jag.navy.mil/distrib/instructions/COLRE G-1972.pdf

3. Dahl K, Mohn C., Maritime Spatial Planning supported by systematic site selection: Applying Marxan for offshore wind power in the western Baltic Sea [online] [15.03.2018] Available at: http://journals.plos.org/plosone/article?id=10.1371/j ournal.pone.0194362

4. Dirba J., Levins N., Pugacevs V., Wind Energy, Riga: Riga Tehnical University, 2006., p.310. 
5. Gilbert A.J., Alexander K., Marine spatial planning and Good Environmental Status: a perspective on spatial and temporal dimensions, 2015, Journal Ecology and Society Vol.20., No.1.

6. Patraiko D. The Shipping Industry and Marine Spatial Planning, 2013 The Nautical Instituts pp.1-14

7. Ships' routeing, Regulation V/10, 1974 SOLAS Convention, [online] [04.03.2018]. Available at: http://www.imo.org/en/OurWork/Safety/Navigation/ Documents/Regulation\%20V-10And11ShipsRouteingAndShipReportingSystems.pdf

8. The energy transition - a great piece of work Offshore wind energy - An overview of activities in Germany, [online] [10.06.2018]. Available at: https://www.erneuerbare-
energien.de/EE/Redaktion/DE/Downloads/offshorewind-

energy.pdf $\% 3 \mathrm{~F}$ _ blob $\% 3$ DpublicationFile $\% 26 \mathrm{v} \% 3$

D2

9. United Nations Convention on the Law of the Sea, [online] [21.02.2018]. Available at: http://www.un.org/depts/los/convention_agreements/ texts/unclos/unclos_e.pdf

10. Vattenfall's Lillgrund Wind Power Plant Technical Description / [online] [12.03.2018]. Available at: https://corporate.vattenfall.se/globalassets/sverige/o $\mathrm{m}$-vattenfall/om-oss/varverksamhet/vindkraft/lillgrund/technical_description _lillgrund_11336934.pdf 